\title{
Graphene Oxide: An Efficient and Recyclable Nano Catalyst for the Synthesis of 2-Substituted Benzimidazoles from Aldehydes and Diamines at Ambient Temperature
}

\author{
Zahra Moniri, Farahnaz K. Behbahani* \\ Department of Chemistry, Karaj Branch, Islamic Azad University, Karaj, Iran
}

\author{
DOI: $10.36348 / \mathrm{sijcms} .2019 . \mathrm{v} 02 \mathrm{i} 07.002$ \\ | Received: 16.11.2019 | Accepted: 23.11.2019 | Published: 28.11.2019
}

*Corresponding author: Farahnaz K. Behbahani

\section{Abstract}

The benzimidazoles skeleton, a category of heterocyclic compounds have important biological and pharmaceutical properties such as antihelminthic, antiulcer, diuretic, anticonvulsant, analgesic, antiulcer, antihypertensive, anticoagulant, anticancer, anti-inflammatory, antimicrobial, antiviral, antiparasitic and antioxidant. On the other hand, graphene oxide due to their operational simplicity, easy work up and inherent non-toxic, and possessing a wide variety of functional groups, such as epoxy, hydroxyl, and carboxyl, pays an important role in organic synthesis. Therefore, in this chapter graphene oxide was investigated as an efficient catalytic system for the preparation of benzimidazole compounds via the condensation reaction of $o$-phenylenediamines with aromatic aldehydes in very good yields at ambient temperature. The results in this method were compared with previously reported in literature respectively. Also graphene oxide was recovered and reused without decreasing in its efficacy for $3^{\text {th }}$ runs.

Keywords: aldehyde, phenylenediamines, graphene oxide, benzimidazoles, synthesis, phenylene diamine, nanocatalyst, 2-substituted, condensation, recyclable.

Copyright @ 2019: This is an open-access article distributed under the terms of the Creative Commons Attribution license which permits unrestricted use, distribution, and reproduction in any medium for non-commercial use (NonCommercial, or CC-BY-NC) provided the original author and source are credited.

\section{INTRODUCTION}

All the heterocyclic compounds are of very interest in pharmaceutical and medicinal chemistry. Out of these useful heterocyclic compounds, the benzfused heterocyclic compound, i.e. benzimidazoles are important pharmacophore and privileged structures in medicinal chemistry. Benzimidazole derivatives exist in various pharmaceutical and biological agents [1, 2] like antiparasitic, thiabendazole, mebendazole and albendazole, antihistaminic norastemizole and mizolastine, as well as antihypertensive telmisartan etc. have been reported and widely used in clinic. A wide variety of biological activities associated with benzimidazoles including antimicrobial and antiprotozoal, antibacterial effects [3], antiallergic activity [4], HIV inhibtors and antiviral effect [5], antiparasitic effect [6], antihypertensive agents [7], cardiotonic activity [8], antiulcer activity [9], antiproliferative activity [10], anti-inflammatory activity [11], antioxidant activity [12], antiprotozoal activity [13], antidiabetic activity [14], diuretic activity [15], anticonvulsant agents [16], DNA binding properties, bovine DHFR and antitumor [17] and anticoagulant [18].
Also, many naturally compounds like vitamin B12 and its derivatives have benzimidazoles skeletone. In addition, it has a close similarity with purine nucleobases structure in DNA and RNA. Due to this similarity, benzimidazole can be easily recognized by various biological systems like enzymes and receptors. On the other hand, benzimidazole core is a privileged structure in pharmaceutical industry and can be found in a plenty of commercial drugs with a wide variety of activities [19]. Among different benzimidazole derivatives, $1 H$-2-substituted benzimidazole moiety is a key structural motif found in numerous well-known drugs such as omeprazole and pantoprazole as antiulcer, albendazole, mebendazole, thiabendazole, flutrimazole, and oxfendazole as anthelmintic, mibefradil and pimobendan as antihypertensive as well as diamidine and enviroxime as antiviral drugs [19]. In addition, these compounds have been employed as important intermediates in organic reactions [20], ligands for asymmetric catalysis [21], and structural subunits of functional materials [22].

Lately, various catalytic systems of Lewis acids have been developed for the synthesis of 
benzimidazoles derivatives with different functional groups highlighting the advantages of their protocol over the other methods [23].

Generally, condensation reaction between $o$ phenylenediamine and carboxylic acids and their derivatives are carried out for the production of benzimidazoles under acidic $\mathrm{pH}$, and in high heating using polyphosphoric acid or by microwave irradiation [24].

In a study, a one-step, sol-gel method was studied for selective preparation of 2-substituted benzimidazoles using high-valent molybdenum ions substituted into the cobalt oxide lattice. Therefore, the synthesis of 2-substituted benzimidazoles was developed using prepared catalyst in the presence of a wide variety of diamines and benzylamine in a one-pot, highly selective, and efficient catalytic protocol high yields. Catalytic activity of $\mathrm{Co}_{3} \mathrm{O}_{4}$ are enhanced by introducing molybdenum as an impurity into the lattice structure, where $\mathrm{Mo}^{6+}$ replaces the $\mathrm{Co}^{3+}$ in the crystal lattice, which alters the surface oxygen vacancies, surface defects, and redox properties of the original material. The advantages this protocol are: being environmentally benign, and cost effective, using an earth-abundant metal, and forming $\mathrm{H}_{2} \mathrm{O}$ and $\mathrm{H}_{2}$ as the sole byproducts [25] (Scheme 1).

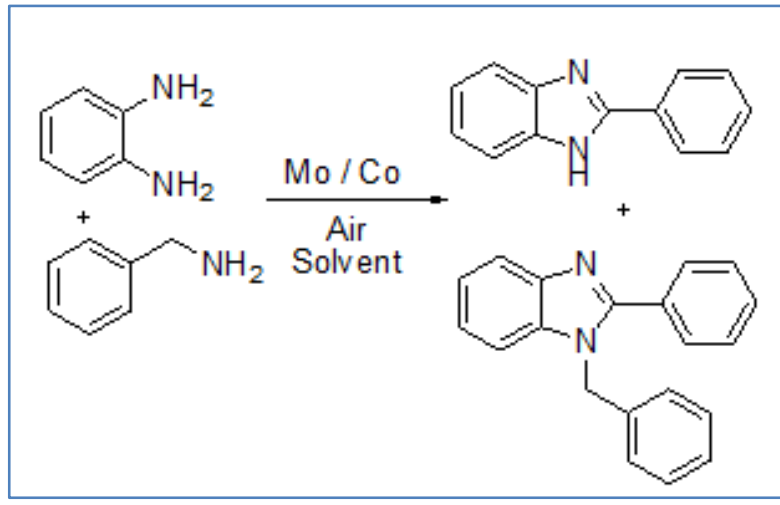

Scheme-1: Conversion and selectivity of $\mathrm{X} \% \mathrm{Mo}-\mathrm{Co}_{3} \mathrm{O}_{4}$ and $\mathrm{CoMoO}_{4}$ catalysts for benzimidazole synthesis reaction

In another study, the condensation reaction of between $o$-phenylenediamine with ketones and aromatic aldehydes resulted benzodiazepine and 1, 2disubstituted benzimidazoles derivatives using $\mathrm{Fe}_{3} \mathrm{O}_{4}$ nanoparticles as a green and recyclable catalyst under solvent free conditions. The advantages of this synthetic method including the use of any toxic organic solvents, easy separation, reusability of the catalyst, high yielding that is very useful in industrial point of view, solventfree condition, separating of the catalyst using external magnetic field and reused for several runs [26] (Scheme 2).

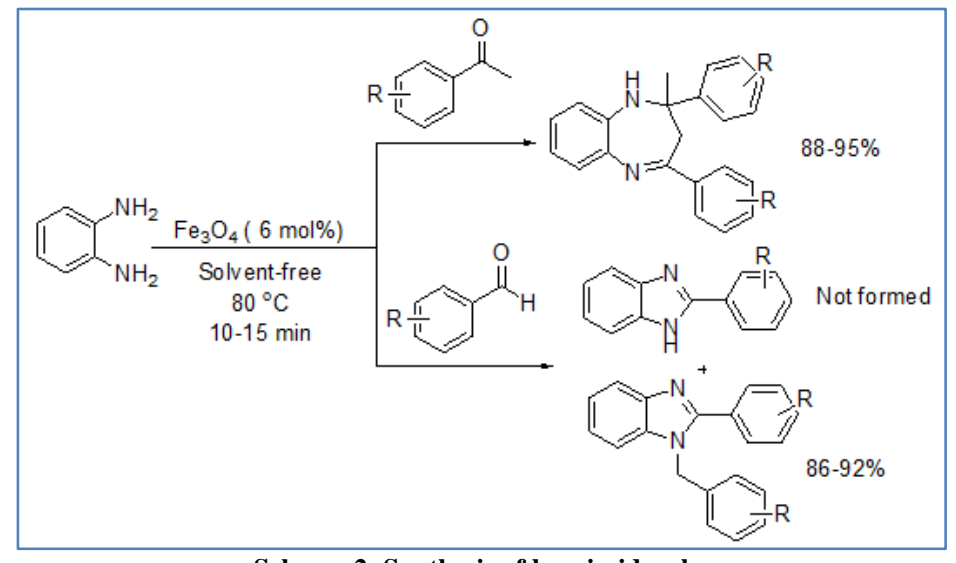

Scheme-2: Synthesis of benzimidazoles

The preparation of 2-substituted benzimidazoles was investigated via condensation of aromatic aldehydes with $o$-phenylenediamine using $25 \% \mathrm{Co} / \mathrm{Ce}-\mathrm{ZrO}_{2}$ as an efficient, green and nano fine particles under solvent free condition and at ambient temperature in high yield [27]. This new method has various advantages such as convenient procedure, easy purification, inexpensive and non-toxic nanoparticles, mild, eco-friendly and green aspects, avoiding hazardous solvents, the use of reusable nanocatalyst, shorter reaction times and high yields. Also 25\% $\mathrm{Co} / \mathrm{Ce}-\mathrm{ZrO}_{2}$ was prepared according to the coprecipitation route and was characterized by techniques such as SEM, XRD, FTIR and so on analysis. The catalyst is reusable and, reusable catalyst was characterized by XRD and FTIR techniques (Scheme 3). 


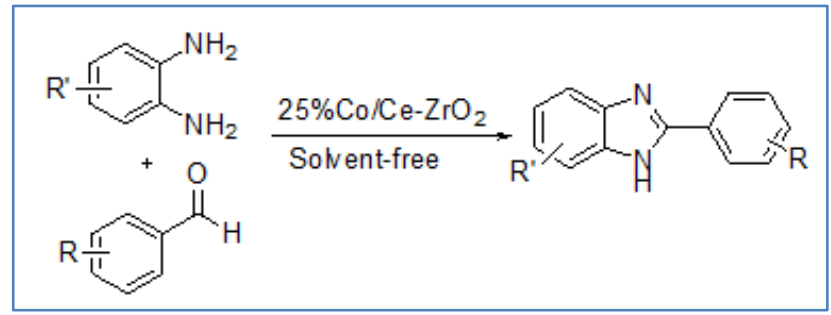

Scheme-3: Synthesis of 2-arylbenzimidazoles by $25 \% \mathrm{Co} / \mathrm{Ce}-\mathrm{ZrO}_{2}$

2-Substituted benzimidazoles were synthesized from the cyclization reaction between benzene-1,2diamine and benzenecarbaldehydes in the presence of $\mathrm{CS}_{2}$, in $\mathrm{CH}_{2} \mathrm{Cl}_{2}$ at room temperature. The reactions were carried out under mild conditions with simple equipment and easy work up [28]. In this protocol a wide range of 2 -substituated $1 H$-benzimidazoles was prepared by using inexpensive and readily available starting materials in simple and efficient procedure, to avoid toxic catalysts and to give nearly quantitative yields without any by-products (Scheme 4).<smiles>Nc1ccccc1N</smiles>

Scheme-4: Synthesis of 2-substituted benzimidazoles

In another study, a series of benzimidazole derivatives were proveded from 1, 2-phenylenediamine and aryl aldehydes at room temperature. The prepared compounds have been characterized on the basis of elemental analysis and various spectroscopic studies such as IR, ${ }^{1} \mathrm{H}$ - and ${ }^{13} \mathrm{C}$-NMR, ESI-MS as well by $\mathrm{X}$ ray single $\mathrm{X}$-ray crystallographic study. Also, interaction of these compounds with CT-DNA has been evaluated with fluorescence experiments and showed significant binding ability. All the synthesized compounds have been examined for their antitumor activities against various human cancer cell lines viz., human breast adenocarcinoma cell line (MCF-7), human leukemia cell line (THP-1), human prostate cancer cell lines (PC-3) and adenocarcinomic human alveolar basal epithelial cell lines (A-549). Interestingly, all the compounds showed significant anticancer activity [29] (Scheme 5).

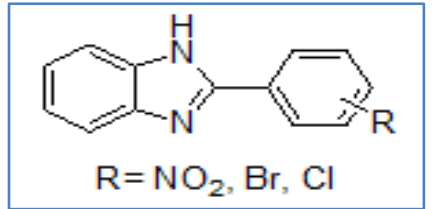

Scheme-5: Benimidazole derivatives

To be very useful benzimidazole skeletone in the medicinal chemistry field, their interactions with biomolecules and biomacromolecules, and a wide range of biological applications such as antimicrobial, antiparasitic, antivirus, anticancer, anti-inflammatory and anti-histamine agents as well as drugs used to treat Alzheimer's disease and hypertension, in another investigation, six new 2,4,6-trisubstituted benzimidazoles were synthesized in the presence of 1,2-phenylendiamine derivatives and carbonyl compounds using acidic and basic reagent [30] (Scheme 6).

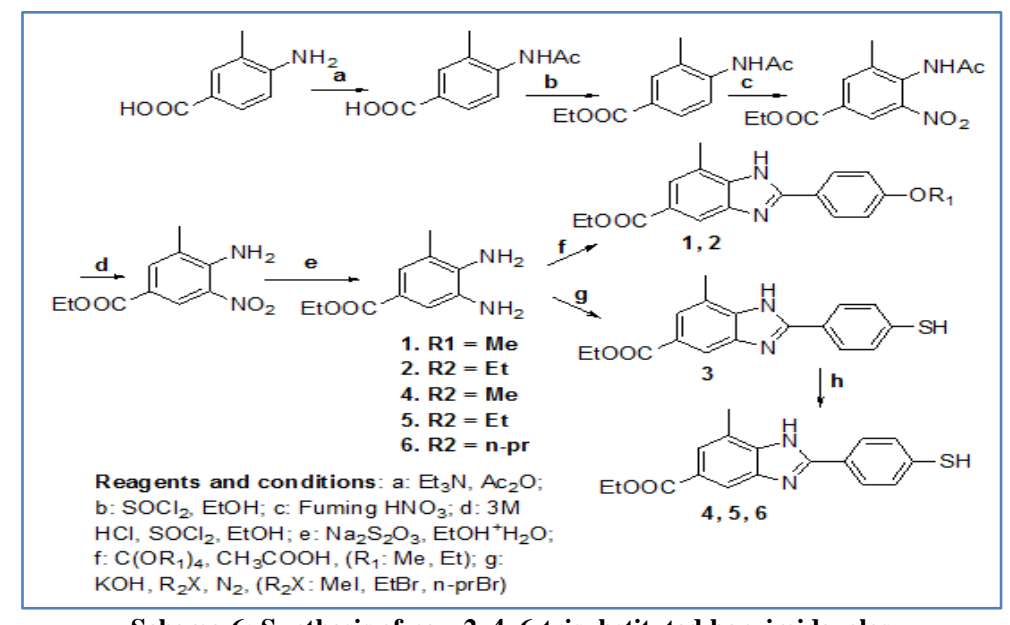

Scheme-6: Synthesis of new 2, 4, 6-trisubstituted benzimidazoles 
Jiang et al. [31] reported an efficient protocol for the synthesis of 2-substituted benzimidazoles from a variety of aliphatic/aromatic/heteroaryl aldehydes and $o$-phenylenediamine derivatives using $\mathrm{NaHSO}_{3}$ in water under reflux condition [31]. Interestingly, the amount of $\mathrm{NaHSO}_{3}$ has a huge effect on the reaction selectivity of 2-substituted benzimidazole and 1, 2-disubstituted benzimidazoles in water. When the amount of the $\mathrm{NaHSO}_{3}$ was more than 11 equivalents, the 2substituted benzimidazole could be highly selectively formed as the sole product. Firstly, $\mathrm{NaHSO}_{3}$ was reacted with aldehyde to obtain the aldehyde sodium bisulfite, which reacted with $o$-phenylenediamine to result in the 2-substituted benzimidazole and inhibited the formation of 1, 2-disubstituted benzimidazole. This protocol solved the poor selectivity problem appearing in traditional method when cyclocondensation between $o$-phenylenediamine and aldehydes. The others advantages this strategy are: simple work up by filtrating, the sole 2-substituted benzimidazole precipitates from reaction mixture at the end of the reaction without further purification, applicable to both electron-rich and electron-poor starting materials, which was successfully used for synthesizing nine novel 2-substituted benzimidazole derivatives containing a 1,2,3-triazole moiety, method scalable, short reaction time, simple and clean separation procedure, high yields and broad substrates scope. These compounds were also characterized by NMR, IR and HRMS spectrum (Scheme 7).

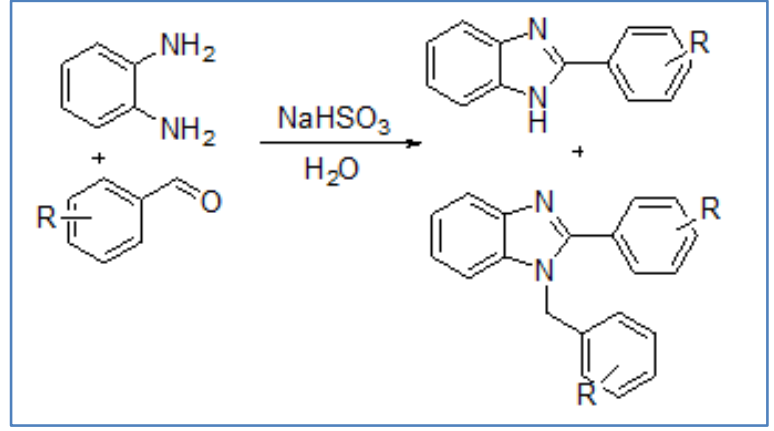

Scheme-7: Synthesis of 2-substituted benzimidazoles using $\mathrm{NaHSO}_{3}$

In another study, Brătulescu developed alkyl halides are feasibly transformed into benzimidazoles derivatives by a domino reaction with $o$ phenylenediamines in the presence of stoichiometric amounts pyridine- $\mathrm{N}$-oxide under solvent-free conditions without need to catalyst in dry medium and little environmental impact. The reaction occurs in dry heterogeneous medium without separation of the intermediates and their purification. The method is an alternative to the expensive and poisonous catalysts, hazardous solvents, and strong acids usually used in all current protocols for the synthesis of benzimidazoles. The benefits of domino sequences cover reduction of waste generated and atom economy [32] (Scheme 8).

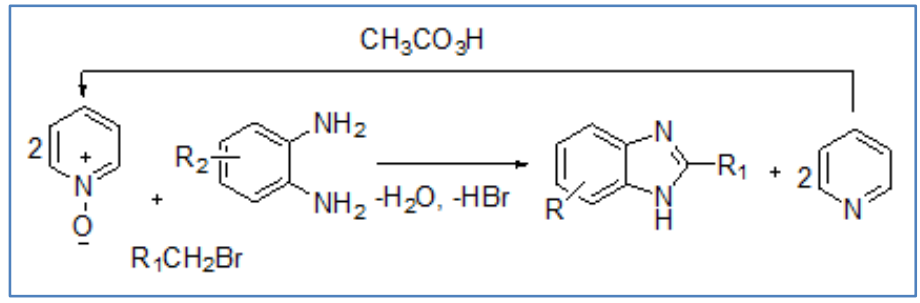

Scheme-8: Conversion of primary alkyl halides to benzimidazoles

The reaction of between 1,2-diaminobenzene and aldehydes were subjected to afford 2-substituted benzimidazoles under aerobic conditions, by simply heating in DMF at $80{ }^{\circ} \mathrm{C}$, utilizing $\mathrm{Ce}\left(\mathrm{NO}_{3}\right)_{3}-6 \mathrm{H}_{2} \mathrm{O}$ as promoter and atmospheric air as an efficient oxidant (Scheme 9). The procedure revealed good-to-excellent yields, new economic and eco-friendly protocol avoiding of the use of toxic metal catalysts, as well as additional bases and oxidants. Additionaly $\mathrm{Ce}\left(\mathrm{NO}_{3}\right)_{3} \cdot 6 \mathrm{H}_{2} \mathrm{O}$ is a very convenient promoter for the reaction of 1,2-diaminobenzene with aldehydes, affording benzimidazoles in good-to-excellent yields after stirring for a few hours under an air atmosphere [33].

$$
\text { ( }
$$

Scheme-9: Preparation of 2-substituted benzimidazoles under aerobic conditions

A magnetic core-shell nanocomposite, $\mathrm{Fe}_{3} \mathrm{O}_{4} @$ Chitosan@ZnO was successfully prepared by in situ chemical precipitation procedure and was employed for the synthesis of 2-substituted benzimidazoles using aryl aldehydes and $o$ - phenylenediamine in moderate-to-excellent isolated yields at room temperature. $\mathrm{Fe}_{3} \mathrm{O}_{4} @ \mathrm{CS} @ \mathrm{ZnO}$ has a clear coreshell structure with magnetic $\mathrm{Fe}_{3} \mathrm{O}_{4}$ (about $160 \mathrm{~nm}$ in diameter) as core, chitosan as the inner shell, and $\mathrm{ZnO}$ as the outer shell, and has high magnetization 
(43.6 emu $\mathrm{g}^{-1}$ ) so that it can be easily separated from the reaction mixture within $4 \mathrm{~s}$ by an external magnetic field as demonstrated by the TEM and the related elemental mapping. The substituted of the natural chitosan shell, instead of the conventional $\mathrm{SiO}_{2}$ shell, and its combination with the active $\mathrm{ZnO}$ makes this nanocomposite green character, environmentally friendly and good catalytic performance in the synthesis of 2-substituted benzimidazoles. The others advantages this catalytic method are: recyclable of the catalyst seven times without appreciable loss of its catalytic activity, easily separation by an external magnet after reaction and exhibited good stability, and making it an attractive candidate for further applications [34] (Scheme 10)

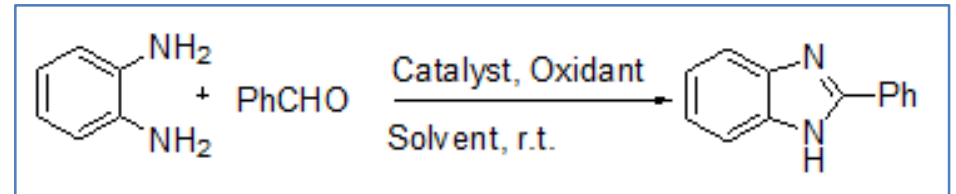

Scheme-10: Synthesis of 2-phenylbenzimidazoles over various $\mathrm{Fe}_{3} \mathrm{O}_{4} @ C_{\text {Chitosan@ }} \mathrm{ZnO}$

The preparation of $1 H$-2-substituted benzimidazole derivatives was described using readily available substrates catalyzed by copper-doped silica cuprous sulfate (CDSCS) as a highly efficient heterogeneous nano-catalyst and diverse 2bromoanilines, aldehydes, and $[\mathrm{bmim}] \mathrm{N}_{3}$ in $\mathrm{DMF}$ at $110{ }^{\circ} \mathrm{C}$ in good-to-excellent yields. The main advantages of this catalytic method are: inexpensive and stable nano-catalyst, simple preparation, recoverable and reusable of the catalyst for many consecutive reaction runs without significant loss of its activity, straightforward, simple, and mild process for synthesis of $1 H$-2-substituted benzimidazoles.

Also, the use of [bmim] $\mathrm{N}_{3}$ as a green source of azide, and the applicability of the method in large scale synthesis make this process as an attractive protocol for the synthesis of structurally diverse benzimidazoles derivatives [35] (Scheme 11).

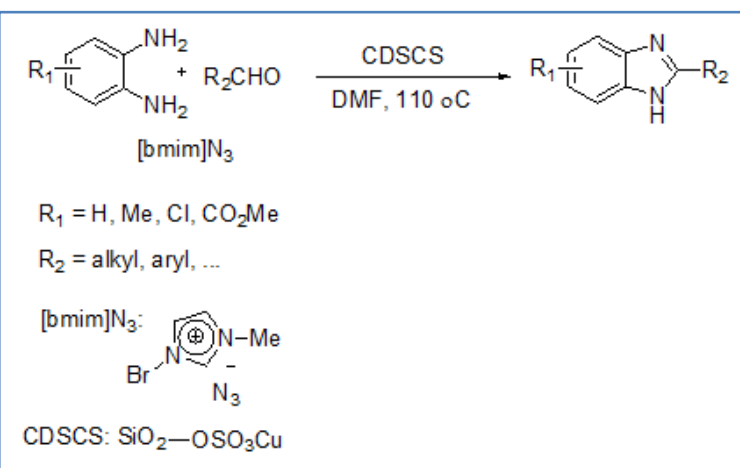

Scheme-11: Three-component synthesis of $1 \mathrm{H}$-2-substituted benzimidazoles using CDSCS

The diversely functionalized benzimidazoles and 2-substituted benzimidazoles were preparation via the imidazolium chloride-catalyzed cyclization of $o$ phenylenediamines with DMF derivatives, and a broad substrate scope for aliphatic, aromatic, and heteroaromatic amides in moderate-to-excellent yields in a facile, general, an efficient and economical approach [36] (Scheme 12).

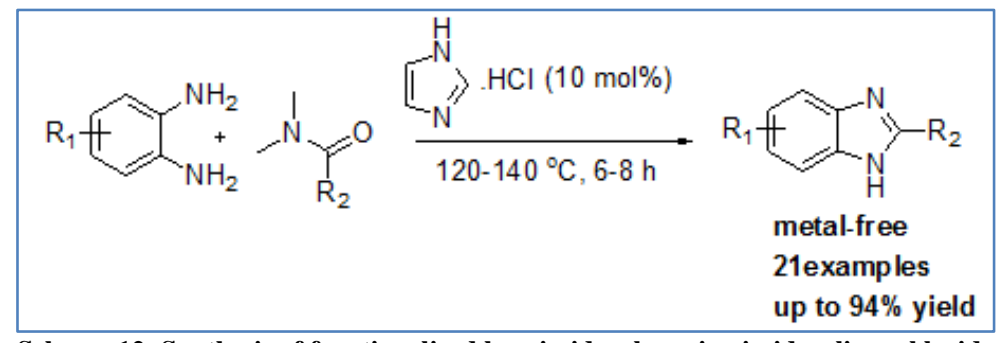

Scheme-12: Synthesis of functionalized benzimidazoles using imidazolium chloride

A series of functionalized benzimidazole derivatives bearing $N$-(4-chloro-or fluorophenyl) pyrrolidin-2-one or $\mathrm{N}$-(4-chloro- or fluorophenyl)aminobutanoic acid moiety were synthesized from condensation reaction between 1,2phenylene diamine and carboxylic acids.

These compounds have a great antibacterial activity, comparable to that of a commercial antibacterial agent oxytetracycline, against Staphylococcus aureus; Escherichia coli, Pseudomonas aeruginosa, and Bacillus cereus were identified. Also, some of the synthesized benzimidazoles revealed significant antioxidant activity such as functionalized benzimidazoles bearing $N$-(4-halophenyl) pyrrolidin-2one or $N$-(4-halophenyl) aminobutanoic acid moiety. 4Amino-5-[2-(1H-benzimidazol-2-yl)-3-(4-

chloroanilino) propyl]-2,4-dihydro-3H-1,2,4-triazole-3thione (40a) was identified as possessing antibacterial activity against $\mathrm{E}$. coli and $\mathrm{P}$. aeruginosa strains higher almost 60 and 30 times, than that of oxytetracycline. 4(1H-Benzimidazol-2-yl)-1-(4-chlorophenyl)-2- 
pyrrolidinone (2a) and N0-[(2-chloro-5nitrophenyl)methylidene]-2-[2-[1-(4-chlorophenyl)-5oxo-3-pyrrolidinyl]-1H-benzimidazol-1- yl]acetohydrazide (2a) exhibit significant antioxidant activity, higher than that of a well-known antioxidant agent ascorbic Acid [37] (Scheme 13).

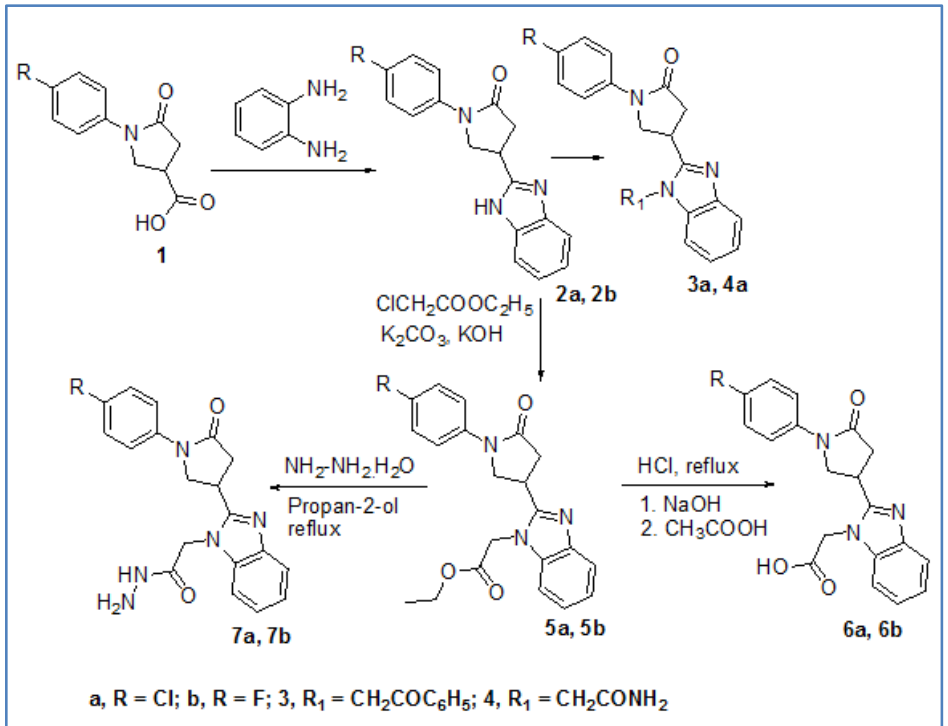

Scheme-13: Synthesis of functionalized benzimidazoles bearing $N$-(4-chloro- or fluorophenyl) pyrrolidin-2-one or $N$-(4-chloro- or fluorophenyl)aminobutanoic acid

The condensation reaction of between $o$ phenylenediamine derivatives and aldehyde derivatives was successfully carried out using catalytic amount of $p$-toluenesulfonic acid coated natural phosphate (NP/PTSA) to afford 2-substituted benzimidazoles under mild conditions in high yields. The advantages this new method includes the use of $\mathrm{NP} / p$-TSA as a reusable, heterogeneous organocatalyst, simple, convenient, and environmentally friendly process, high yield, recoverable catalyst for successive condensation without loss an appreciable catalytic activity after the fourth run, and easy work-up procedure [18] (Scheme 14).

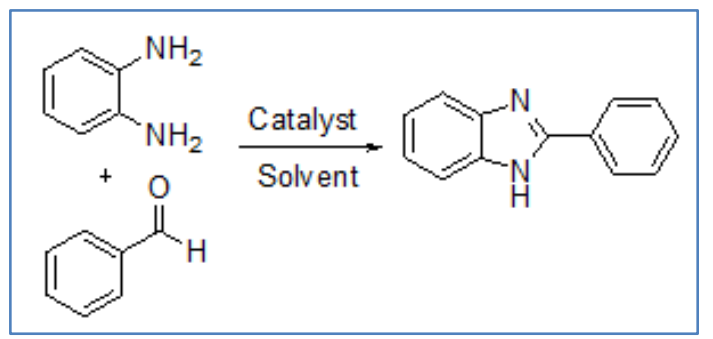

Scheme-14: Reaction for the synthesis of 2-phenyl- $1 \mathrm{H}$-benzimidazole

In another study, $o$-phenylenediamnes and aryl aldehydes were subjected to prepare 2-substituted benzimidazoles using aerosil supported ionic liquid phase acronymed [BMIM]PF6@aerosil in high yields under mild reaction conditions (Scheme 15). This procedure has several advantages including high yields, effective simplicity, less reaction time and smooth reaction conditions. Also, the prepared benzimidazoles revealed good antifungal activity against Candida albicans (NCIM-3466) and Aspergiillus niger (NCIM3495). Additionally, molecular docking studies of synthesized benzimidazoles revealed hydrogen bonding interactions with receptor enzyme of acetylcholinesterase (AChE) and so prepared benzimidazoles act as inhibitors for AChE [39].

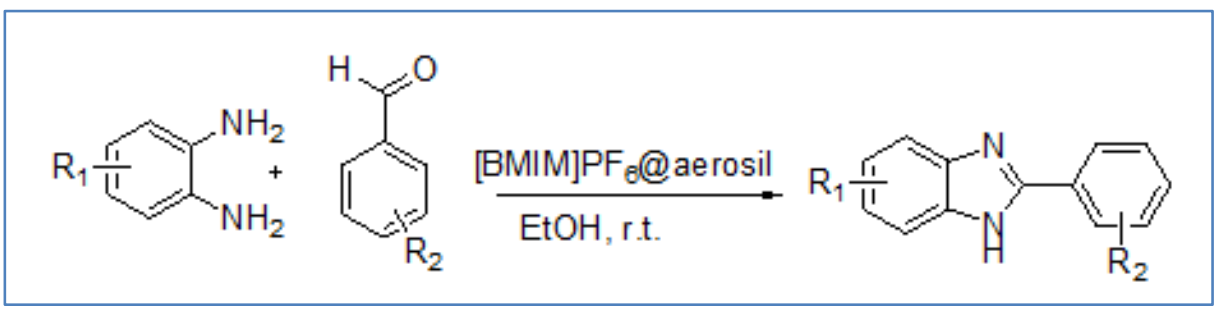

Scheme-15: [BMIM]pf6@aerosil reaction of o-phenylenediamines and aryl aldehydes 
The synthesis of 2-substituted benzimidazole derivatives is reported using $o$-phenylenediamine and various substituted benzoyl chlorides in the presence of green catalyst water extract of papaya bark ash (WEPBA) at room temperature. This method provides several advantages such as completely green, economic, giving high yields and minimizing use of hazardous solvents. Also, the separated product does not require any kind of chromatographic purification. The homogeniety of the products were examined by using ${ }^{1} \mathrm{H},{ }^{13} \mathrm{C}$ NMR and mass spectrometry [40].
In another study, the synthesized new poly ( $N$ heterocyclic carbene $\mathrm{Cu}$ complex) immobilized on nano silica, (CuII-NHCs)n@ $\mathrm{nSiO}_{2}$ was used for the preparation of benzimidazoles, benzothiazoles, 1, 2, 3 triazoles, bis-triazoles and Sonogashira-Hagihara cross-coupling reactions. The (CuII-NHCs)n@ $\mathrm{nSiO}_{2}$ heterogeneous catalyst showed the advantages such as high efficiency, good-to-excellent yield, short reaction times, easy separation and high reusability of the catalyst [25] (Scheme 16).

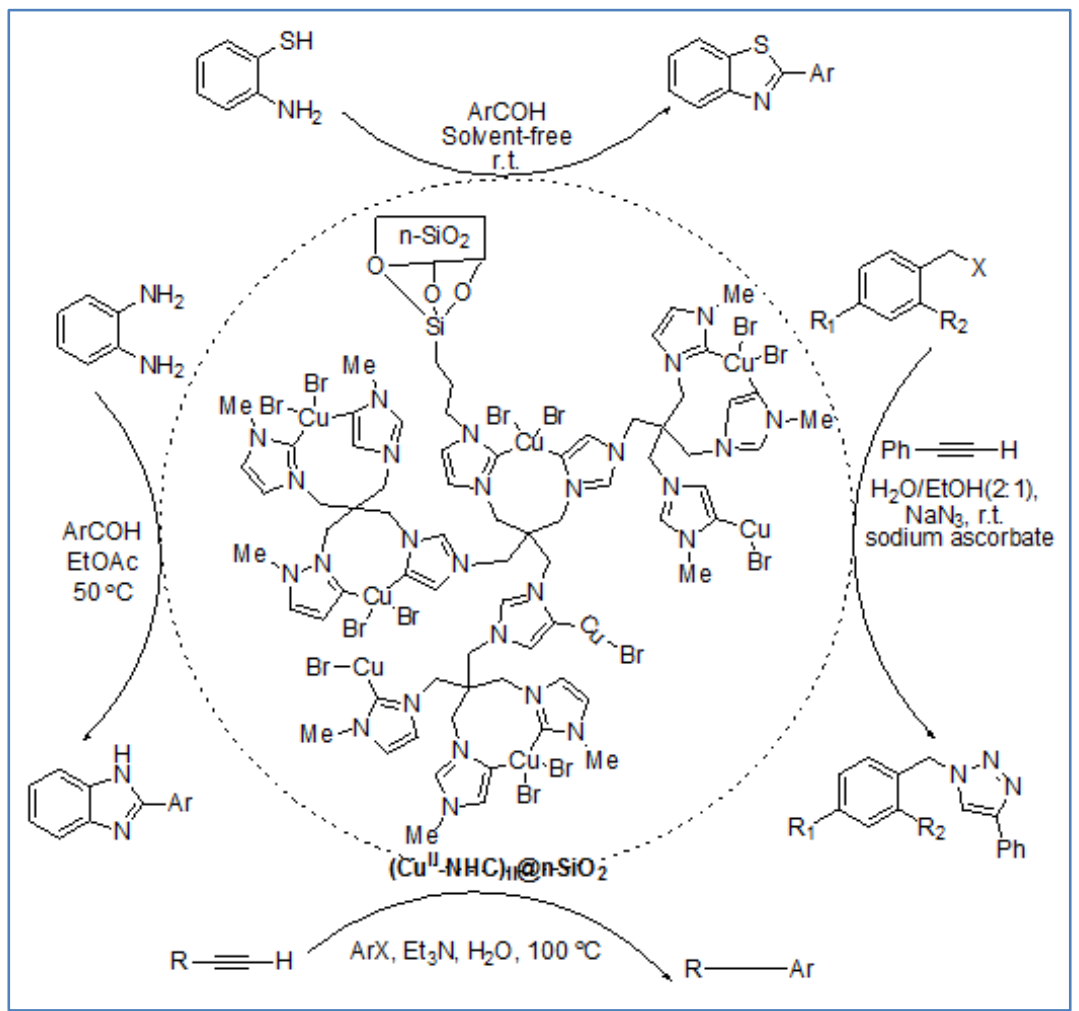

Scheme-16: Synthesis of benzimidazoles, benzothiazoles, 1, 2, 3-triazoles and Sonogashira-Hagihara cross-coupling reactions catalyzed by (CuII-NHCs)n@nSiO

In some of these methods, the catalysts are occasionally destroyed in the work-up and cannot be recovered and reused. Therefore, the study needs for a better condition for the preparation of these compounds in terms of the use of recoverable catalyst, and mild reaction condition [41-46].

On the other hand, graphene oxide (GO) due to their operational simplicity, easy work up and inherent non-toxic, interestingly revealed a great activity owing to its privileged lamellar flexible structure and possessing a wide variety of functional groups, such as epoxy, hydroxyl, and carboxyl [47]. Because of their high specific surface areas as well as excellent stabilities, GO has payed attention as a sufficient material to support a variety of ions or biomolecules, and GO supported catalysts have been used for a variety of chemistry reactions [48]. But many researchers ignored that the carboxyl groups of GO that play an important role in organic reactions which can be applied as solid acids to catalyze the providing of heterocyclic compounds. To the best of our knowledge, only very limited ways about using GO as solid acid catalyst has been investigated and the application of GO served as the lone catalyst in the synthesis of 2substituted benzimidazoles from aldehydes and $o$ phenylene diamines has not been reported before. Ongoing our last studies [49-51], we wish to investigate the viability of using GO as the lone catalyst to synthesize 2-substituted benzimidazoles using ary aldehydes and diamines in the presence of graphene oxide as solid acid catalyst at ambient temperature (Scheme 17). 


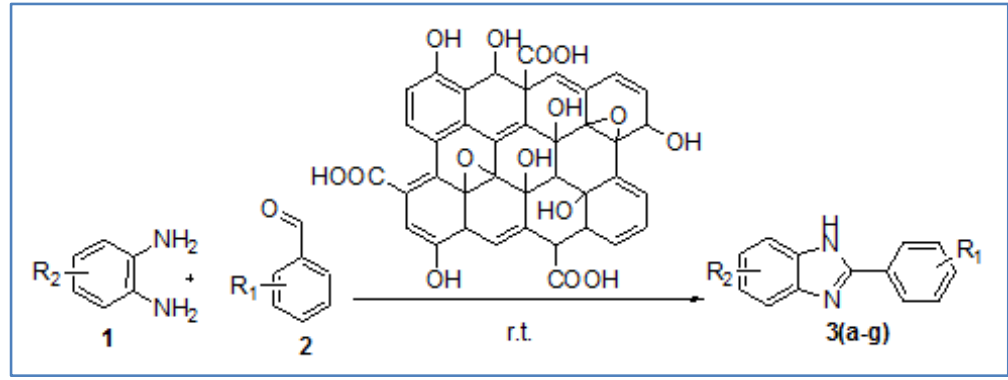

Scheme-17: Synthesis of 2-substituted benzimidazole derivatives

\section{Experimental}

Melting points were measured by using the capillary tube method with an electro thermal 9200 apparatus. IR spectra were recorded on Perkin Elmer FT-IR spectrometer did scanning between 4000-400 $\mathrm{cm}^{-1}$. ${ }^{1} \mathrm{H}$ NMR spectra were obtained on Bruker DRX$300 \mathrm{MHz} \mathrm{NMR}$ instrument in $\mathrm{CDC1}_{3}$. Analytical TLC of all reactions was performed on Merck precoated plates (silica gel 60F-254 on aluminium). All compounds are known and spectra and physical data were compared with those of authentic samples [52, 27]. Graphene oxide was synthesized according to procedure reported in literature [53]. FT-IR spectra of graphene oxide has been shown in figure 1, part a.

Preparation of 2-substituted benzimidazole derivatives using graphene oxide. General procedure: In a one neck flask, aryl aldehydes ( $1 \mathrm{mmol})$, diamines (1 mmol) and ethanol $(5 \mathrm{ml})$ were mixed with graphene oxide $(0.05 \mathrm{~g})$ at ambient temperature. After completion of the reaction monitored by TLC (ethyl acetate:nhexane; 1:3), GO was filtrated off and the product was obtained as a solid compound after evaporation of ethanol. For more purification, the residue was recrystallized by ethanol.

\section{Recyclability of the catalyst}

The reusability of the catalyst was also studied. After completing of the reaction (entry 2, Table 1 ), the catalyst was removed by filtration and washed with diethyl ether. The recycled catalyst could be subjected to a third or even more times. In this reaction, the catalyst can easily be recovered and reused after three runs (Table 3). FTIR analysis was shown that the catalytic activity of the catalyst were almost the same as those of the freshly used catalyst (Fig. 1). We believe that recover $\mathrm{GO}$ can be used for more runs without decreasing of its activity.

Table-3: Reusability of the graphene oxide in the synthesis of 2-(4-chloro phenyl)-5-methyl-Hbenzimidazole

\begin{tabular}{|l|l|l|}
\hline Entry & Runs & Yield\% \\
\hline 1 & fresh & 94 \\
\hline 2 & $1^{\text {th }}$ & 92 \\
\hline 3 & $2^{\text {nd }}$ & 91 \\
\hline
\end{tabular}

${ }^{\text {a }}$ Yields of the isolated products from the reaction of benzaldehyde ( $1 \mathrm{mmol})$, o-phenylenediamine $(1 \mathrm{mmol})$ and $\mathrm{GO}(0.05 \mathrm{~g})$ at room temperature in $25 \mathrm{~min}$

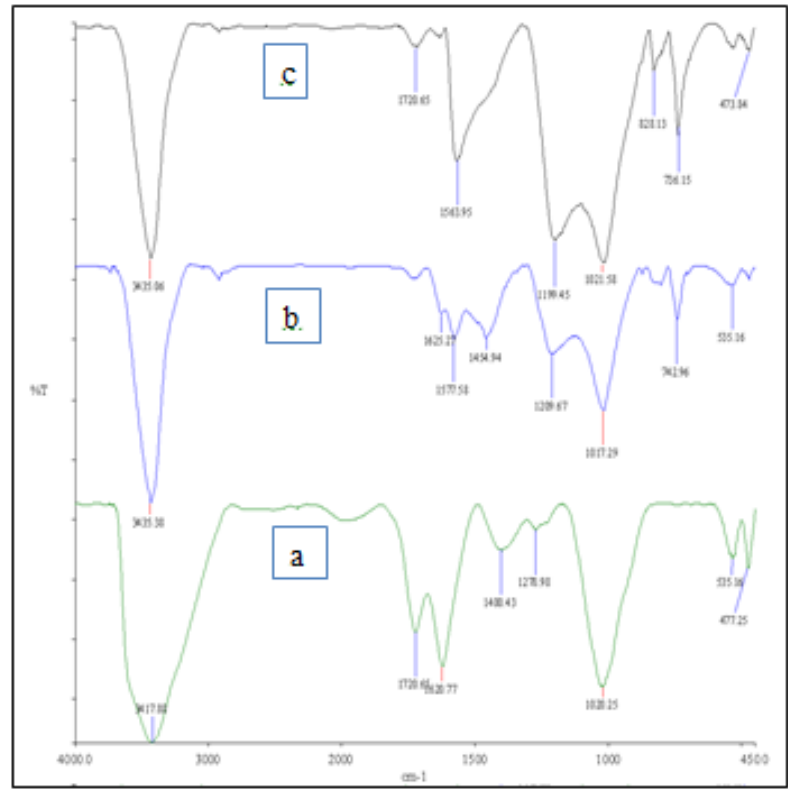

Fig-1: FT-IR spectra of graphene oxide catalyst. a, GO fresh; b, GO $1^{\text {st }}$ run; c, GO $2^{\text {nd }}$ run

\section{Physical and spectra data}

2-Phenyl-1H-benzimidazole (3a). IR ( $\mathrm{KBr}$ $\left./ \mathrm{cm}^{-1}\right)$ : 3050.84, 1586.66, 1473.16, 1463.00, 1446.40, 763.69. ${ }^{1} \mathrm{HNMR}\left(\mathrm{CDCl}_{3}, 300 \mathrm{MHz}, \delta \mathrm{ppm}\right): 13.15$ (s, $1 \mathrm{H}), 8.22-8.19(\mathrm{~d}, 2 \mathrm{H}), 7.61-7.47(\mathrm{~m}, 5 \mathrm{H}), 7.21-7.17$ $(\mathrm{m}, 2 \mathrm{H})$.

2-(3-Nitro phenyl)-1H-benzimidazole (3c). IR $\left(\mathrm{KBr} / \mathrm{cm}^{-1}\right): 3460.79,3182.16, \quad 1621.60,1522.33$, 1348.97, 740.10. ${ }^{1} \mathrm{HNMR}\left(\mathrm{CDCl}_{3}, 300 \mathrm{MHz}, \delta \mathrm{ppm}\right)$ : $8.77(\mathrm{~s}, 1 \mathrm{H}), 8.64(\mathrm{~s}, 1 \mathrm{H}), 8.33-8.30(\mathrm{~d}, 1 \mathrm{H}), 8.24-8.22$ $(\mathrm{d}, 1 \mathrm{H}), 7.69-7.63(\mathrm{~m}, 1 \mathrm{H}), 7.14-7.11(\mathrm{~m}, 2 \mathrm{H}), 6.83-$ $6.78(\mathrm{~m}, 2 \mathrm{H})$.

2-(3,4-Dimethoxy)-1H-benzimidazole (3d). IR $\left(\mathrm{KBr} / \mathrm{cm}^{-1}\right): 3583.21, \quad 3190.30, \quad 2936.87, \quad 2836.90$, $1609.50,1590.25,1499.76,1244.50,1022.28,742.12$. ${ }^{1} \mathrm{HNMR}\left(\mathrm{CDCl}_{3}, 300 \mathrm{MHz}, \delta \mathrm{ppm}\right): 8.45$ (s, 1H), 7.62$6.73(\mathrm{~m}, 7 \mathrm{H}), 3.98-3.94$ (s, 6H).

2-(4-Chloro phenyl)-5-nitro-H-benzimidazole (3f). IR $\left(\mathrm{KBr} / \mathrm{cm}^{-1}\right): 3433.89,3369.04,1602.52$, 1481.53, 1340.10, 1313.93, 821.68, 735.11. ${ }^{1} \mathrm{HNMR}$ $\left(\mathrm{CDCl}_{3}, 300 \mathrm{MHz}, \delta \mathrm{ppm}\right): 7.59(\mathrm{~m}, 2 \mathrm{H}), 8.64(\mathrm{~m}, 1 \mathrm{H})$, $7.74(\mathrm{~d}, 1 \mathrm{H}), 8.09-8.12(\mathrm{~m}, 1 \mathrm{H}), 8.18-8.20(\mathrm{~m}, 2 \mathrm{H})$, $8.45(\mathrm{~s}, 1 \mathrm{H}), 13.60(\mathrm{~s}, 1 \mathrm{H})$. 
2-(4-Chloro

phenyl)-5-methyl-Hbenzimidazole $(3 \mathrm{~g})$. IR $\left(\mathrm{KBr} / \mathrm{cm}^{-1}\right)$ : 3055.65, 2918.64, 2796.61, 1676.44, 1442.98, 1091.73, 801.82, 703.06. ${ }^{1} \mathrm{HNMR}\left(\mathrm{CDCl}_{3}, 300 \mathrm{MHz}, \delta \mathrm{ppm}\right): 2.5(\mathrm{~s}, 3 \mathrm{H}), 7.4(\mathrm{~m}$, $1 \mathrm{H}), 7.6(\mathrm{~s}, 1 \mathrm{H}), 7.75(\mathrm{~m}, 4 \mathrm{H}), 8.25(\mathrm{~m}, 2 \mathrm{H}), 12.4(\mathrm{~s}$, $1 \mathrm{H})$.

\section{RESULTS AND DISCUSSION}

To achieve scope of the reaction, various arylenediamines 1 were subjected to react with aldehyde 2 in order to investigate the reaction scope and several representative results are depicted in Table 1.
As summarized in Table 1, various types of $o$ phenylenediamines with electron-donating and electron-withdrawing groups on the aromatic ring were converted to the corresponding substituted benzimidazoles in the presence of a catalytic amount of GO readily and rapidly. The electronic nature of the groups on the aromatic ring of $o$-phenylenediamines was relevant to the yield of 3 . The substituent on ring of aldehydes has no influence on the reaction course. Finally, high yields, simple and comfortable separate operation provided several special advantages this protocol.

Table-1: Synthesis of 2-substituted benzimidazole derivatives using graphene oxide

\begin{tabular}{|c|c|c|c|c|c|c|}
\hline Entry & $\mathbf{R}_{1}$ & $\mathbf{R}_{2}$ & Product & Time (min) & Yield\% & m.p $\left({ }^{\circ} \mathrm{C}\right)[$ ref.] \\
\hline 1 & $\mathrm{H}$ & $\mathrm{H}$ & $3 \mathbf{a}$ & 20 & 95 & 288-291 Behbahani et al. [27] \\
\hline 2 & $4-\mathrm{Cl}$ & $\mathrm{H}$ & $\mathbf{3 b}$ & 25 & 94 & $\begin{array}{l}\text { 289-291 } \\
\text { Behbahani et al. [27] }\end{array}$ \\
\hline 3 & $3-\mathrm{NO}_{2}$ & $\mathrm{H}$ & $3 c$ & 30 & 95 & $\begin{array}{l}\text { 202-203 } \\
\text { Behbahani et al. [27] }\end{array}$ \\
\hline 4 & $3,4-(\mathrm{OMe})_{2}$ & $\mathrm{H}$ & 3d & 30 & 80 & $\begin{array}{l}\text { 234-237 } \\
\text { Behbahani et al. [27] }\end{array}$ \\
\hline 5 & $4-\mathrm{OMe}$ & $\mathrm{H}$ & $3 e$ & 35 & 90 & $\begin{array}{l}\text { 224-226 } \\
\text { Behbahani et al. [27] }\end{array}$ \\
\hline 6 & $4-\mathrm{Cl}$ & $4-\mathrm{NO}_{2}$ & 3f & 50 & 87 & $\begin{array}{l}\text { 279-281 } \\
\text { Behbahani et al. [52] }\end{array}$ \\
\hline 7 & $4-\mathrm{Cl}$ & $4-\mathrm{CH}_{3}$ & $3 g$ & 45 & 90 & $\begin{array}{l}224-225 \\
\text { Behbahani et al. }[52,54]\end{array}$ \\
\hline
\end{tabular}

The suggested mechanism for the graphene oxide-catalyzed synthesis of 2-substituted benzimidazoles has been described by a sequence of reactions as shown in Scheme 18. This involves formation of GO-activated of aldehyde carbonyl groups
1 following nucleophilic attacking of $O$ phenylenediamine 3 to 2 afford benzilidine iminium 4 . After ring closure into a five-membered ring and oxidation of the dihydrobenzimidazole 5 by air, the benzimidazoles 6 were obtained.

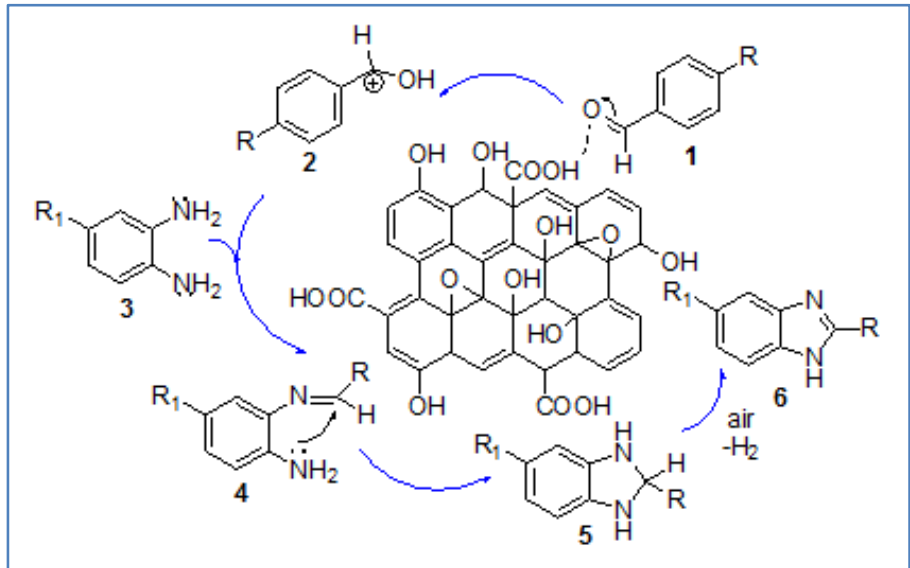

Scheme-18: Suggested mechanism for the synthesis of 2-substituted benzimidazoles using GO

To compare the worthy of this catalytic method with those of previously reported the results of the formation of 2-phenyl-1H-benzimidazoles (entry 1, Table 1) were compiled in the presence of a variety of nano-catalysts. From the results given in Table 2, the advantages of our method are evident, regarding the catalyst amounts, short reaction and saving energy which are very important in chemical industry especially when it is combined with easy separation and high yield. 
Table-2: Synthesis of 2-phenyl-1H- benzimidazoles by various nano-catalysts

\begin{tabular}{|l|l|l|l|l|l|l|}
\hline Entry & Catalyst $(\mathbf{m o l} \%$ or g) & Solvent & Time & Temp. $\left({ }^{\circ} \mathbf{C}\right)$ & Yield \% & Ref. \\
\hline 1 & $75 \% \mathrm{Fe} / \mathrm{CeO}_{2}-\mathrm{ZrO}_{2}$ & $\mathrm{EtOH}$ & $2 \mathrm{~h}$ & r.t & 90 & Behbahani et al. $[$ [52] \\
\hline 2 & $\mathrm{Nano}-\mathrm{ZnO}(10 \mathrm{~mol} \%)$ & $\mathrm{EtOH}$ & $100 \mathrm{~min}$ & 80 & 88 & Teimouri et al. $[44]$ \\
\hline 3 & Nano- $\mathrm{MnFe}_{2} \mathrm{O}_{4}(10 \mathrm{~mol} \%)$ & $\mathrm{MeOH}$ & $4.0 \mathrm{~h}$ & r.t & 92 & Brahmachari et al. $[46]$ \\
\hline 4 & $25 \% \mathrm{Co} / \mathrm{Ce}-\mathrm{ZrO}_{2}(0.1 \mathrm{~g})$ & Free & $10 \mathrm{~min}$ & r.t & 98 & Behbahani et al. [46] \\
\hline 5 & Graphene oxide $(0.05 \mathrm{~g})$ & $\mathrm{EtOH}$ & $20 \mathrm{~min}$ & r.t & 95 & Present work \\
\hline
\end{tabular}

\section{CONCLUSIONS}

In conclusion, graphene oxide is employed as an excellent catalyst for the preparation of benzimidazole derivatives. This novel and practical method has the advantages such as mild reaction conditions, short reaction times, high yields of products, easy workup, and inexpensive of catalyst in comparison with the previously reported methods.

\section{REFERENCES}

1. Kotresh, K. M., \& Belachew, M. G. (2014). Study on waste tyre rubber as concrete aggregates. International Journal of Scientific Engineering and Technology, 3(4), 433-436.

2. Varnado Jr, C. D., Lynch, V. M., \& Bielawski, C. W. (2009). 1, 1'-Bis (N-benzimidazolylidene) ferrocene: synthesis and study of a novel ditopic ligand and its transition metal complexes. Dalton Transactions, (35), 7253-7261.

3. Rathee, P. S., Dhankar, R., Bhardwaj, S., Gupta, M., \& Kumar, R. (2011). Synthesis and antimicrobial studies of substituted 2phenylbenzimidazole derivatives. Journal of Applied Pharmaceutical Science, 1(10), 14.

4. Nakano, H., Inoue, T., Kawasaki, N., Miyataka, H., Matsumoto, H., Taguchi, T., ... \& Satoh, T. (1999). Synthesis of benzimidazole derivatives as antiallergic agents with 5-lipoxygenase inhibiting action. Chemical and pharmaceutical bulletin, 47(11), 1573-1578.

5. Fonseca, T., Gigante, B., Marques, M. M., Gilchrist, T. L., \& De Clercq, E. (2004). Synthesis and antiviral evaluation of benzimidazoles, quinoxalines and indoles from dehydroabietic acid. Bioorganic \& medicinal chemistry, 12(1), 103-112.

6. Serafin, B., Borkowska, G., Główczyk, J., Kowalska, I., \& Rump, S. (1989). Potential antihypertensive benzimidazole derivatives. Polish journal of pharmacology and pharmacy, 4l(1), 89-96.

7. Bethke, T., Brunkhorst, D., der Leyen, H. V., Meyer, W., Nigbur, R., \& Scholz, H. (1988). Mechanism of action and cardiotonic activity of a new phosphodiesterase inhibitor, the benzimidazole derivative adibendan (BM 14.478), in guinea-pig hearts. Naunyn-Schmiedeberg's archives of pharmacology, 337(5), 576-582.

8. Khan, F. R., \& Asnani, A. J. (2011). Synthesis and antiulcer, anti-secretory activity of some new substituted

2-(pyrimidinylsulfinyl) benzamidazoles derivatives. International Journal of Research in pharmaceutical and biomedical sciences, 2(2), 695-700.

9. Al-Douh, M. H., Sahib, H. B., Osman, H., Hamid, S. A., \& Salhimi, S. M. (2012). Anti-proliferation effects of benzimidazole derivatives on HCT-116 colon cancer and MCF-7 breast cancer cell lines. Asian Pacific Journal of Cancer Prevention, 13(8), 4075-4079.

10. Lazer, E. S., Matteo, M. R., \& Possanza, G. J. (1987). Benzimidazole derivatives with atypical antiinflammatory activity. Journal of medicinal chemistry, 30(4), 726-729.

11. Aydin, S., Beis, R., \& Can, Ö. D. (2003). Analgesic and antispasmodic activities of 2-(2nitro-phenyl)-1H-benzimidazole 5-carboxylic acid: evidence for the importance of the 2-(0substituted phenyl) group. Die Pharmazie-An International Journal of Pharmaceutical Sciences, 58(6), 405-408.

12. Kazimierczuk, Z., Upcroft, J. A., Upcroft, P., Górska, A., Starosciak, B., \& Laudy, A. (2002). Synthesis, antiprotozoal and antibacterial activity of nitro-and halogeno-substituted benzimidazole derivatives. ACTA BIOCHIMICA POLONICAENGLISH EDITION-, 49(1), 185-196.

13. Bhise, U. N., Bhirud, S. B., \& Mashelkarb, U. C. (2008). Synthesis, anti-bacterial, anti-asthmatic and anti-diabetic activities of novel $\mathrm{N}$-substituted 2-(4-styrylphenyl)-1H-benzimidazole and $\mathrm{N}$ substituted-3 [4-(1H-benzimidazole-2-yl)-phenyl]acrylic acid tert-butyl ester. ARKIVOC, 14, 37-49.

14. Pashinskiǔ, V. G., Romanova, T. V., Mukhina, N. A., Shkrabova, L. V., \& Tetenchuk, K. P. (1978). Diuretic activity of benzimidazole urea derivatives. Farmakologiia i toksikologiia, 41(2), 196-199.

15. Ng, R. A., Guan, J., Alford Jr, V. C., Lanter, J. C., Allan, G. F., Sbriscia, T., ... \& Sui, Z. (2007). Synthesis and SAR of potent and selective androgen receptor antagonists: 5, 6-Dichlorobenzimidazole derivatives. Bioorganic \& medicinal chemistry letters, 17(3), 784-788.

16. Thakurdesai, P. A., Wadodkar, S. G., \& Chopade, C. T. (2007). Synthesis and anti-inflammatory activity of some benzimidazole-2-carboxylic acids. Pharmacologyonline, 1, 314-329.

17. Mederski, W. W., Dorsch, D., Anzali, S., Gleitz, J., Cezanne, B., \& Tsaklakidis, C. (2004). Halothiophene benzimidazoles as P1 surrogates of inhibitors of blood coagulation factor 
Xa. Bioorganic \& medicinal chemistry letters, 14(14), 3763-3769.

18. Rathod, C. P., Rajurkar, R. M., \& Thonte, S. S. (2013). Benzimidazole synthesis and biological evaluation: A review. Indo Am J Pharm Res, 2323-2329.

19. Kleeman, A., Engel, J., Kutscher, B., Reichert., D. (1999). Pharmaceutical Substances, third ed., Thieme, Stuttgart.

20. Molander, G.A., Ajayi, K. (2012). Oxidative condensations to form benzimidazole-substituted potassium organotrifluoroborates. Org

Lett 14:4242-4245.

https://doi.org/10.1021/ol301956p

21. Figge, A., Altenbach, H.J., Brauer, D.J., Tielmann, P. (2002). Synthesis and resolution of 2-(2diphenylphosphinyl-naphthalen-1-yl)-1-isopropyl1H-benzoimidazole; a new atropisomeric P, Nchelating ligand for asymmetric catalysis. Tetrahedron: Asym 13:137-144. https://doi.org/10.1016/S0957-4166(02)00079-4

22. Asensio, J.A., Gómez-Romero, P. (2005). Recent Developments on Proton Conduc-ting Poly (2, 5benzimidazole)(ABPBI) Membranes for High Temperature Poly-mer Electrolyte Membrane Fuel Cells. Fuel Cells, 5:336-343. https://doi.org/10.1002/fuce.200400081

23. Rekha, M., Hamza, A., Venugopal, B. R., \& Nagaraju, N. (2012). Synthesis of 2-substituted benzimidazoles and 1, 5-disubstituted benzodiazepines on alumina and zirconia catalysts. Chinese Journal of Catalysis, 33(2-3), 439-446.

24. Czarny, A., Wilson, W. D., \& Boykin, D. W. (1996). Synthesis of mono-cationic and dicationic analogs of hoechst 33258. Journal of heterocyclic chemistry, 33(4), 1393-1397.

25. Khajehzadeh, M., Moghadam, M., \&

Jamehbozorgi, S. (2019). Synthesis and characterization of a new poly $(\mathrm{N}$-heterocyclic carbene $\mathrm{Cu}$ complex) immobilized on nanosilica,(CuII-NHCs) n@ nSiO2, and its application as an efficient and reusable catalyst in the synthesis of benzimidazoles, benzothiazoles, 1, 2, 3-triazoles, bis-triazoles and sonogashirahagihara reactions. Inorganica Chimica Acta, 485, 173-189.

26. Jamatia, R., Saha, M., \& Pal, A. K. (2014). An efficient facile and one-pot synthesis of benzodiazepines and chemoselective 1, 2disubstituted benzimidazoles using a magnetically retrievable $\mathrm{Fe} 3 \mathrm{O} 4$ nanocatalyst under solvent free conditions. RSC Advances, 4(25), 1282612833.

27. Behbahani, F. K., Rezaee, E., \& Fakhroueian, Z. (2014). Synthesis of 2-substituted benzimidazoles using $25 \% \mathrm{Co} / \mathrm{Ce}-\mathrm{ZrO} 2$ as a heterogeneous and nanocatalyst. Catalysis letters, 144(12), 21842190.
28. Gladysz, J. A., Reza Safaei, H., \& Nouri, S. (2014). An Unexpected Role of Carbon Disulfide: A New and Efficient Method for the Synthesis of 2-Substituted Benzimidazoles. Helvetica Chimica Acta, 97(11), 1539-1545.

29. Azam, M., Khan, A. A., Al-Resayes, S. I., Islam, M. S., Saxena, A. K., Dwivedi, S., .. \& Kruszynski, R. (2015). Synthesis and characterization of 2-substituted benzimidazoles and their evaluation as anticancer agent. Spectrochimica Acta Part A: Molecular and Biomolecular Spectroscopy, 142, 286-291.

30. Han, X. F., Chen, M. M., \& Zhou, Z. M. (2015). Synthesis of several new 2-substituted benzimidazoles. $J \quad$ Chem Res 39:407-409. https://doi.org/10.3184/174751915X14357663684 593

31. Jiang, Y. Q., Jia, S. H., Li, X. Y., Sun, Y. M., Li, W., Zhang, W. W., \& Xu, G. Q. (2018). An efficient NaHSO 3-promoted protocol for chemoselective synthesis of 2-substituted benzimidazoles in water. Chemical Papers, 72(5), 1265-1276.

32. Brătulescu, G. (2017). Mild, one-pot preparation of 2-substituted benzimidazoles from organic halides. Synthetic Communications, 47(8), 811817.

33. Martins, G. M., Puccinelli, T., Gariani, R. A., Xavier, F. R., Silveira, C. C., \& Mendes, S. R. (2017). Facile and efficient aerobic one-pot synthesis of benzimidazoles using $\mathrm{Ce}$ (NO3) 3 . $6 \mathrm{H} 2 \mathrm{O}$ as promoter. Tetrahedron Letters, 58(20), 1969-1972.

34. Tian, F., Niu, L., Chen, B., Gao, X., Lan, X., Huo, L., \& Bai, G. (2017). A novel magnetic core-shell nanocomposite Fe 304@ chitosan@ ZnO for the green synthesis of 2-benzimidazoles. Journal of Nanoparticle Research, 19(10), 330.

35. Behrouz, S. (2018). Copper-doped silica cuprous sulfate: A highly efficient heterogeneous nanocatalyst for one-pot three-component synthesis of 1-H-2-substituted benzimidazoles from 2bromoanilines, aldehydes, and [bmim] N3. Journal of Saudi Chemical Society, 22(3), 261-268.

36. Gan, Z., Tian, Q., Shang, S., Luo, W., Dai, Z., Wang, H., ... \& Yuan, J. (2018). Imidazolium chloride-catalyzed synthesis of benzimidazoles and 2-substituted benzimidazoles from $\mathrm{O}$ phenylenediamines and DMF derivatives. Tetrahedron, 74(52), 7450-7456.

37. Tumosienè, I., Peleckis, A., Jonuškienè, I., Vaickelionienè, R., Kantminienè, K., Šiugždaitė, J., ... \& Mickevičius, V. (2018). Synthesis of novel 1, 2-and 2-substituted benzimidazoles with high antibacterial and antioxidant activity. Monatshefte für Chemie-Chemical Monthly, 149(3), 577-594.

38. Belkharchach, S., Elayadi, H., Ighachane, H., Sebti, S., Ali, M. A., \& Lazrek, H. B. (2018). pToluenesulfonic acid coated natural phosphate as 
an efficient catalyst for the synthesis of 2substituted benzimidazole. Journal of Chemical Research, 42(12), 614-617.

39. Sonawane, B. D., Rashinkar, G. S., Sonawane, K. D., Dhanavade, M. J., Sonawane, V. D., \& Patil, S. V. (2018). Aerosil-Supported Ionic-LiquidPhase (ASILP) Mediated Synthesis of 2Substituted Benzimidazole Derivatives as AChE Inhibitors. ChemistrySelect, 3(20), 5544-5551.

40. Kantharaju, K., \& Hiremath, P. B. (2018). OnePot, Green Approach Synthesis of 2-Aryl Substituted Benzimidazole Derivatives Catalyzed by Water Extract of Papaya Bark Ash. Asian Journal of Chemistry, 30(7), 1634-1638.

41. Dhakshinamoorthy, A., Kanagaraj, K., \& Pitchumani, K. (2011). Zn2+-K10-clay (clayzic) as an efficient water-tolerant, solid acid catalyst for the synthesis of benzimidazoles and quinoxalines at room temperature. Tetrahedron letters, 52(1), 69-73.

42. Riadi, Y., Mamouni, R., Azzalou, R., El Haddad, M., Routier, S., Guillaumet, G., \& Lazar, S. (2011). An efficient and reusable heterogeneous catalyst animal bone meal for facile synthesis of benzimidazoles, benzoxazoles, and benzothiazoles. Tetrahedron letters, 52(27), 34923495.

43. Chari, M. A., Shobha, D., \& Sasaki, T. (2011). Room temperature synthesis of benzimidazole derivatives using reusable cobalt hydroxide (II) and cobalt oxide (II) as efficient solid catalysts. Tetrahedron letters, 52(43), 5575-5580.

44. Teimouri, A., Chermahini, A. N., Salavati, H., \& Ghorbanian, L. (2013). An efficient and one-pot synthesis of benzimidazoles, benzoxazoles, benzothiazoles and quinoxalines catalyzed via nano-solid acid catalysts. Journal of Molecular Catalysis A: Chemical, 373, 38-45.

45. Abdollahi-Alibeik, M., Moosavifard, M., \& Poorirani, S. (2013). Synthesis of 2-Substituted Benzimidazoles in the Presence of Polyaniline Nanoparticles Doped With 12-Tungstophosphoric Acid as Reusable Heterogeneous Catalyst. Synthesis and Reactivity in Inorganic, Metal-Organic, and Nano-Metal Chemistry, 43(10), 1365-1371.

46. Brahmachari, G., Laskar, S., \& Barik, P. (2013). Magnetically separable MnFe 2 O 4 nano- material: an efficient and reusable heterogeneous catalyst for the synthesis of 2-substituted benzimidazoles and the extended synthesis of quinoxalines at room temperature under aerobic conditions. RSC Advances, 3(34), 14245-14253.

47. Liu, Y., Dong, X., \& Chen, P. (2012). Biological and chemical sensors based on graphene materials. Chemical Society Reviews, 41(6), 2283 2307.

48. Yang, X., Chen, C., Li, J., Zhao, G., Ren, X., \& Wang, X. (2012). Graphene oxide-iron oxide and reduced graphene oxide-iron oxide hybrid materials for the removal of organic and inorganic pollutants. Rsc Advances, 2(23), 8821-8826.

49. Oskooie, H. A., Heravi, M. M., Sadnia, A., Jannati, F., \& Behbahani, F. K. (2008). H 2 SO 4/Silicagel: Highly Efficient Catalyst for the Synthesis of $\alpha$-Aminonitriles Using Trimethysilyl Cyanide.Monatshefte für Chemie-Chemical Monthly, 139(1), 27-29.

50. Heravi, M. M., Behbahani, F. K., Daraie, M., \& Oskooie, H. A. (2009). Fe $\left(\mathrm{ClO}_{4}\right)_{3} \cdot 6 \mathrm{H}_{2} \mathrm{O}$ : a mild and efficient catalyst for one-pot three component synthesis of $\beta$-acetamido carbonyl compounds under solvent-free conditions. Molecular diversity.

51. Behbahani, F. K., \& Lotfi, A. (2013). Catalytic performance of $\mathrm{SiO} 2$-supported $\mathrm{Fe}(\mathrm{ClO} 4) 3$. $6 \mathrm{H} 2 \mathrm{O}$ in synthesis of 2-substituted benzimidazoles. European Chemical Bulletin, 2(9), 694-697.

52. Behbahani, F. K., Ziaei, P., Fakhroueian, Z., \& Doragi, N. (2011). An efficient synthesis of 2 arylbenzimidazoles from o-phenylenediamines and arylaldehydes catalyzed by $\mathrm{Fe} / \mathrm{CeO} 2-\mathrm{ZrO} 2$ nano fine particles. Monatshefte für ChemieChemical Monthly, 142(9), 901-906.

53. Wang, Y., Sang, R., Zheng, Y., Guo, L., Guan, M., \& Wu, Y. (2017). Graphene oxide: An efficient recyclable solid acid for the synthesis of bis (indolyl) methanes from aldehydes and indoles in water. Catalysis Communications, 89, 138-142.

54. Weerakkody, C., Rathnayake, D., He, J., Dutta, B., Kerns, P., Achola, L., \& Suib, S. L. (2019). Enhanced Catalytic Properties of Molybdenum Promoted Mesoporous Cobalt Oxide: StructureSurface-Dependent Activity for Selective Synthesis of 2-Substituted Benzimidazoles. ChemCatChem, 11(1), 528-537. 